\title{
FIELD MEASUREMENTS OF DIRECT AND REARVIEW-MIRROR GLARE FROM LOW-BEAM HEADLAMPS
}

\author{
Michael Sivak \\ Michael J. Flannagan \\ Brandon Schoettle \\ Yoshihiro Nakata
}


FIELD MEASUREMENTS OF DIRECT AND REARVIEW-MIRROR GLARE FROM LOW-BEAM HEADLAMPS

Michael Sivak

Michael J. Flannagan

Brandon Schoettle

Yoshihiro Nakata

The University of Michigan

Transportation Research Institute

Ann Arbor, Michigan 48109-2150

U.S.A.

Report No. UMTRI-2001-3

January 2001 
Technical Report Documentation Page

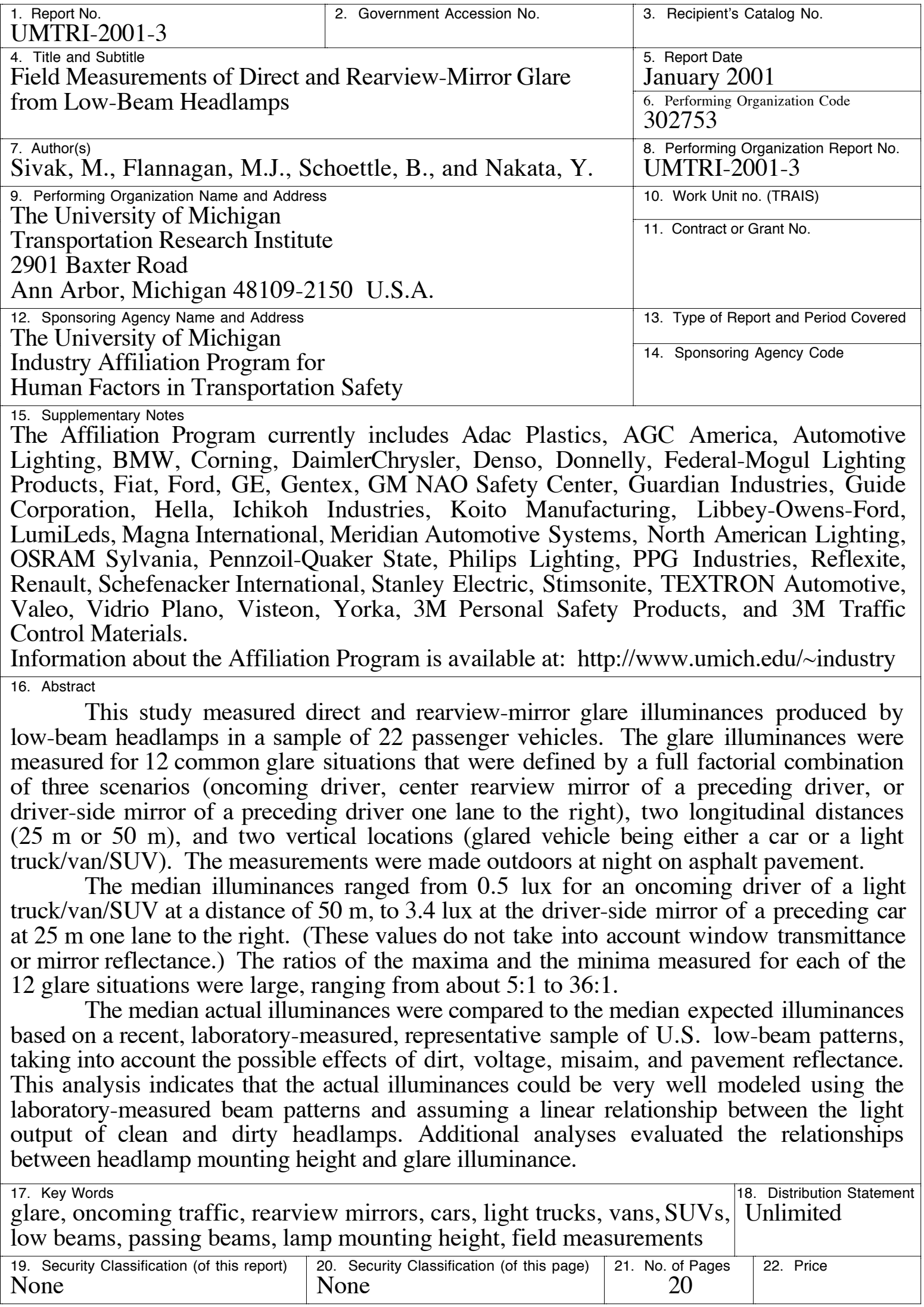




\section{ACKNOWLEDGMENTS}

Appreciation is extended to the members of the University of Michigan Industry Affiliation Program for Human Factors in Transportation Safety for support of this research. The current members of the Program are:

Adac Plastics

AGC America

Automotive Lighting

BMW

Corning

DaimlerChrysler

Denso

Donnelly

Federal-Mogul Lighting Products

Fiat

Ford

GE

Gentex

GM NAO Safety Center

Guardian Industries

Guide Corporation

Hella

Ichikoh Industries

Koito Manufacturing

Libbey-Owens-Ford

LumiLeds

Magna International

Meridian Automotive Systems

North American Lighting

OSRAM Sylvania

Pennzoil-Quaker State

Philips Lighting

PPG Industries

Reflexite

Renault

Schefenacker International

Stanley Electric

Stimsonite

TEXTRON Automotive

Valeo

Vidrio Plano

Visteon

Yorka

3M Personal Safety Products

3M Traffic Control Materials 


\section{CONTENTS}

Acknowledgments ............................................................

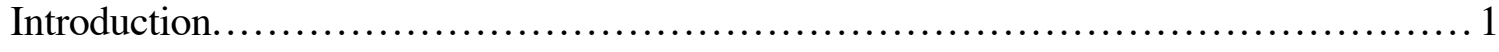

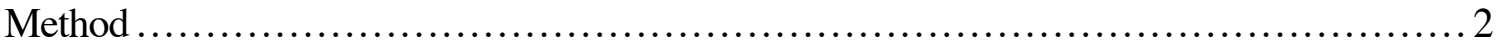

Results ................................................................ 7

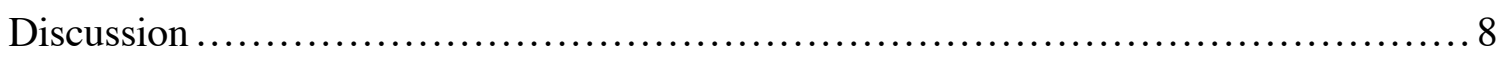

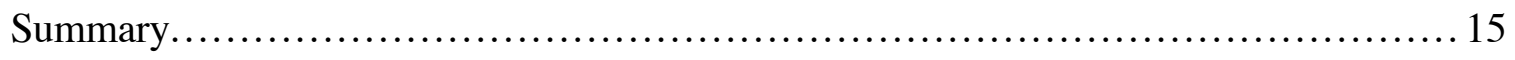

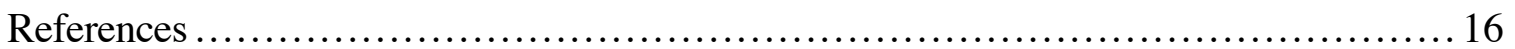




\section{INTRODUCTION}

Two recent studies provide market-weighted information about low-beam headlighting patterns in the U.S. and Europe (Sivak, Flannagan, Kojima, and Traube, 1997; Sivak, Flannagan, and Schoettle, 2000). The photometric data in these two reports are in the form of detailed candela matrixes. From this information, it is possible to calculate the amount of light that would be expected to be directed to a particular point in space, such as the eyes of an oncoming driver or the eyes of a preceding driver via a rearview mirror. To achieve this would first require calculating, for the particular point of interest, the horizontal and vertical angles with respect to each headlamp location. Next, luminous intensity would be looked up in the respective candela matrix for the calculated angles. Finally, the sum of the two candela values (one for each headlamp), divided by the square of the distance, would provide an estimate of the illuminance reaching the point of interest.

However, the available photometric data are based on laboratory measurements for new and clean headlamps that are correctly aimed and energized at a controlled voltage level. Consequently, the calculations described above would not take into account several important factors that influence headlamp illumination, such as lamp voltage (Ammerlaan and Vellekoop, 1996; Silva, 1998; Sivak, Flannagan, Traube, and Miyokawa, 1998), lens dirt (Cox, 1968; Rumar, 1974; Padmos and Alferdinck, 1988), misaim (Padmos and Alferdinck, 1988; Sivak, Flannagan, and Miyokawa, 1999a), and pavement reflectance (Jackett and Fisher, 1974; Sabey, 1972). It is possible to correct the originally calculated values by using estimated effects of the intervening factors. Another approach would involve obtaining measurements under actual field conditions, and that is the approach taken in this study.

Specifically, this study was designed to obtain a set of field glare illuminance readings (representing the glare experienced by oncoming drivers and the glare experienced by preceding drivers via rearview mirrors), and to compare these values with expected illuminances based on laboratory photometric data. 


\section{METHOD}

\section{Experimental setup}

Measurements were made in an asphalt-paved parking area near the UMTRI building. The experimental setup was designed to represent 12 common glare situations that were defined by a full factorial combination of 3 lateral locations, 2 longitudinal locations, and 2 vertical locations (see Figure 1).

Lateral locations. There were 3 lateral locations, representing vehicles in 3 different lanes of traffic:

(1) Direct glare for an oncoming driver in the left adjacent lane.

(2) Indirect glare via inside, center mirror for a preceding driver in the same lane.

(3) Indirect glare via outside, driver-side mirror for a preceding driver in the right adjacent lane.

Longitudinal locations. Two distances were used, representing vehicles separated by $25 \mathrm{~m}$ and $50 \mathrm{~m}$.

Vertical locations. There were two heights above the pavement, representing two types of glared vehicles (passenger cars and light trucks/vans/SUVs).

Table 1 lists the spatial coordinates of all 12 test locations. These coordinates are based on the data from Sivak, Flannagan, Budnik, Flannagan, and Kojima (1996) for the locations of driver eyes; Reed, Lehto, and Flannagan (2000) for the locations of rearview mirrors on cars; and Reed, Ebert, and Flannagan (2001) for the locations of rearview mirrors on light trucks, vans, and SUVs.

The lateral coordinates differ slightly between the two classes of vehicles for both driver eye positions (a difference of $0.07 \mathrm{~m}$ ) and driver-side mirrors (a difference of $0.12 \mathrm{~m}$ ). Because small changes in horizontal angles have only minor effects on the light output, these differences were disregarded and in each case were averaged to derive the common lateral coordinates for both types of vehicles. 


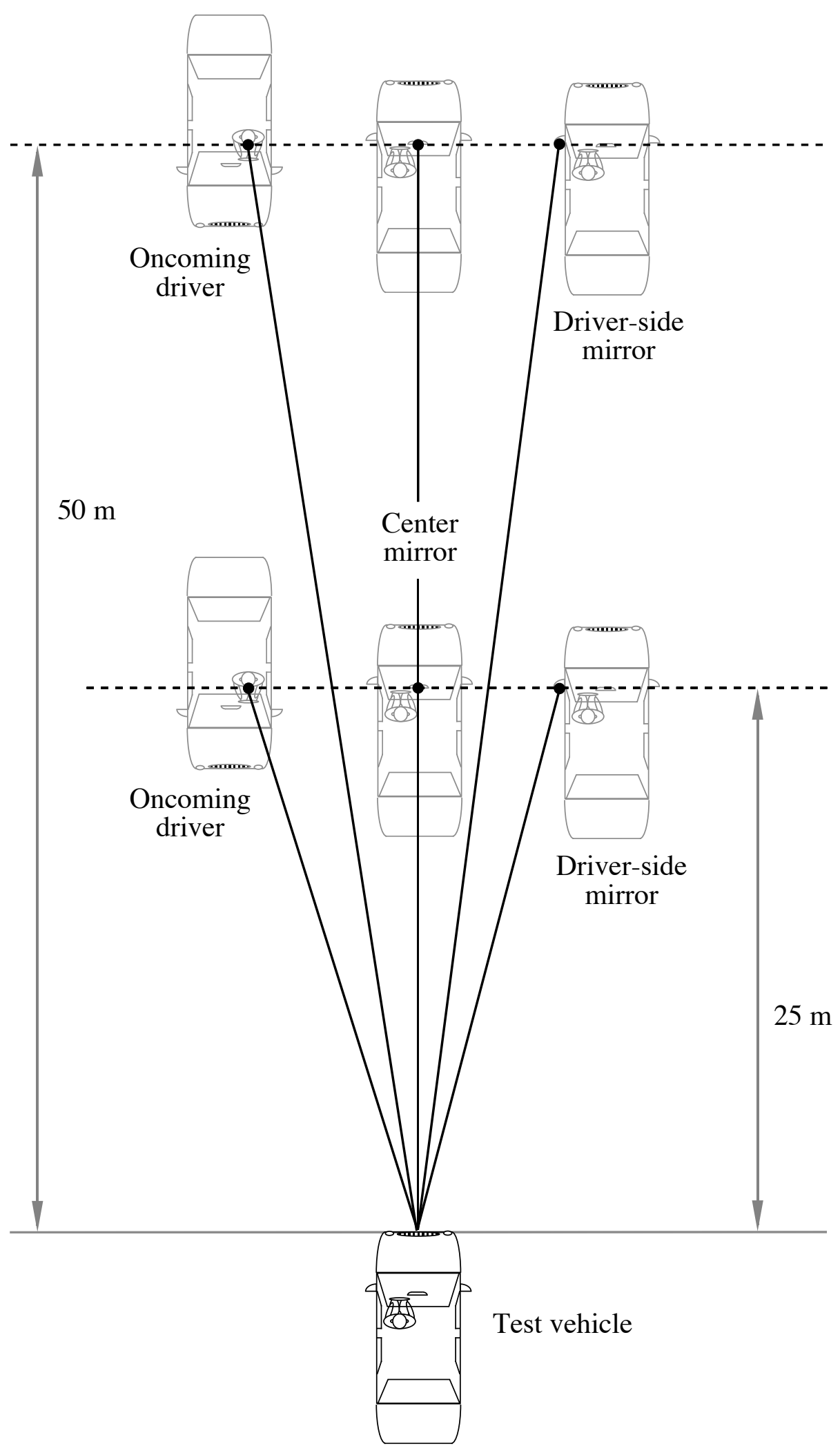

Figure 1. A schematic diagram of the experimental setup. For each of the six positions shown, measurements were taken at two different heights above the pavement, for a total of 12 measurements. (See text for details.) 
Table 1

The three coordinates of the 12 test locations. The longitudinal distances are from the headlamps, the lateral distances from the centerline of the test vehicle, and the vertical distances from the ground. All distances are in meters.

\begin{tabular}{|c|c|c|c|c|c|}
\hline \multirow{3}{*}{$\begin{array}{c}\text { Location } \\
1\end{array}$} & \multirow{2}{*}{\multicolumn{2}{|c|}{ Abbreviated description* }} & \multicolumn{3}{|c|}{ Coordinate } \\
\hline & & & Lateral & Longitudinal & Vertical \\
\hline & Direct glare & $25 \mathrm{~m} \mathrm{car}$ & -3.28 & 25 & 1.11 \\
\hline 2 & Driver-side mirror & $25 \mathrm{~m} \mathrm{car}$ & 2.73 & 25 & 0.94 \\
\hline 3 & Center mirror & $25 \mathrm{~m} \mathrm{car}$ & 0 & 25 & 1.19 \\
\hline 4 & Direct glare & $25 \mathrm{~m}$ truck & -3.28 & 25 & 1.42 \\
\hline 5 & Driver-side mirror & $25 \mathrm{~m}$ truck & 2.73 & 25 & 1.18 \\
\hline 6 & Center mirror & $25 \mathrm{~m}$ truck & 0 & 25 & 1.48 \\
\hline 7 & Direct glare & $50 \mathrm{~m} \mathrm{car}$ & -3.28 & 50 & 1.11 \\
\hline 8 & Driver-side mirror & $50 \mathrm{~m} \mathrm{car}$ & 2.73 & 50 & 0.94 \\
\hline 9 & Center mirror & $50 \mathrm{~m} \mathrm{car}$ & 0 & 50 & 1.19 \\
\hline 10 & Direct glare & $50 \mathrm{~m}$ truck & -3.28 & 50 & 1.42 \\
\hline 11 & Driver-side mirror & $50 \mathrm{~m}$ truck & 2.73 & 50 & 1.18 \\
\hline 12 & Center mirror & $50 \mathrm{~m}$ truck & 0 & 50 & 1.48 \\
\hline
\end{tabular}

*The vehicle entry indicates the glared vehicle. "Truck" stands for "light truck, van, or SUV." 


\section{Procedure}

The photometric measurements were taken at least 1 hour after sunset. It took about 30 minutes to take the 12 measurements for each vehicle.

Each vehicle was positioned by the volunteer subject, with the assistance of two experimenters outside of the vehicle. The vehicle was centered within a lane $3.66 \mathrm{~m}$ wide, with the headlamps at the baseline longitudinal distance $(0 \mathrm{~m})$.

The driver was instructed to turn on the low-beam headlamps, leave the engine running for the duration of the measurements, and remain in the vehicle. At the time of recruitment, the drivers were asked not to make any adjustments to their headlamps (such as cleaning, aiming, or bulb replacement) just because they were participating in this study. Before the photometric measurements were taken, the headlamp type and mounting locations were recorded.

The photometric measurements were then recorded using a tripod-mounted illuminance meter (Minolta T-1). The tripod was calibrated to allow for vertical height adjustments as needed. Because the illuminance meter was not inside a vehicle, the measured illuminance values do not take into account window transmittance or mirror reflectance.

The existing fixed lighting in the vicinity of the experimental setup was turned off during the measurements. Ambient light levels were recorded several times during each session. They averaged 0.14 lux. The average ambient light levels for each experimental session were subtracted from the recorded measurements in that session to obtain the actual illuminance values.

\section{Vehicle sample}

The sample for this study consisted of 22 vehicles owned by UMTRI employees or UMTRI. The sample included 16 passenger cars (73\%) and 6 light trucks, vans, and SUVs (27\%). The model years of the vehicles ranged from 1989 to 2000 (see Table 2). The sample included 15 vehicles with two-lamp systems (68\%) and 7 vehicles with fourlamp systems (32\%). A breakdown by the optical design of the lamps is shown in Table 3 , and a breakdown by bulb type is shown in Table 4. The median headlamp mounting height (center to ground) was $0.64 \mathrm{~m}$, and the median headlamp separation (center to center) was $1.13 \mathrm{~m}$. 
Table 2

Model years of the tested vehicles.

\begin{tabular}{|l|c|c|c|c|c|c|c|c|c|c|}
\hline & \multicolumn{10}{|c|}{ Model year } \\
\cline { 2 - 12 } & 1989 & 1990 & 1991 & 1992 & 1993 & 1994 & 1995 & 1997 & 1998 & 2000 \\
\hline \hline Count & 1 & 1 & 3 & 2 & 2 & 2 & 2 & 3 & 2 & 4 \\
\hline Percent & 5 & 5 & 14 & 9 & 9 & 9 & 9 & 14 & 9 & 18 \\
\hline
\end{tabular}

Table 3

Headlamp construction in the tested vehicles.

\begin{tabular}{|l|c|c|c|}
\hline \multirow{2}{*}{} & \multicolumn{3}{|c|}{ Headlamp construction } \\
\cline { 2 - 4 } & Standard & Complex reflector & Projector \\
\hline \hline Count & 16 & 5 & 1 \\
\hline Percent & 73 & 23 & 5 \\
\hline
\end{tabular}

Table 4

Low-beam bulbs in the tested vehicles.

\begin{tabular}{|l|c|c|c|c|c|}
\hline \multirow{2}{*}{} & \multicolumn{5}{|c|}{ Bulb type } \\
\cline { 2 - 6 } & HB1 & HB2 & HB4 & HB5 & D2S \\
\hline \hline Count & 6 & 3 & 6 & 6 & 1 \\
\hline Percent & 27 & 14 & 27 & 27 & 5 \\
\hline
\end{tabular}




\section{RESULTS}

The photometric readings are summarized in Tables 5 and 6 . Table 5 lists the median illuminances for the 12 conditions of interest, while Table 6 provides the ratios between the maximum and minimum illuminances.

Table 5

Median illuminance readings in lux for each of the 12 conditions.

\begin{tabular}{|l|c|c|c|c|}
\hline \multirow{2}{*}{\begin{tabular}{c}
\multirow{2}{*}{$\begin{array}{c}\text { Glare } \\
\text { scenario }\end{array}$} \\
\cline { 2 - 5 }
\end{tabular}} & \multicolumn{3}{|c|}{ Glared vehicle type } \\
\cline { 2 - 5 } & $25 \mathrm{~m}$ & $50 \mathrm{~m}$ & $25 \mathrm{~m}$ & $50 \mathrm{~m}$ \\
\hline \hline Oncoming driver & 1.25 & 0.57 & 1.03 & 0.47 \\
\hline Center mirror & 2.56 & 1.11 & 1.97 & 0.82 \\
\hline Driver-side mirror & 3.39 & 2.48 & 2.36 & 1.59 \\
\hline
\end{tabular}

Table 6

Ratios of the maximum and minimum illuminance readings for each of the 12 conditions.

\begin{tabular}{|l|c|c|c|c|}
\hline \multirow{2}{*}{\begin{tabular}{c}
\multirow{2}{*}{$\begin{array}{c}\text { Glare } \\
\text { scenario }\end{array}$} \\
\cline { 2 - 5 }
\end{tabular}} & \multicolumn{3}{|c|}{ Car } & \multicolumn{3}{c|}{ Light truck, van, or SUV } \\
\cline { 2 - 5 } & $25 \mathrm{~m}$ & $50 \mathrm{~m}$ & $25 \mathrm{~m}$ & $50 \mathrm{~m}$ \\
\hline \hline Oncoming driver & 7.6 & 7.3 & 4.8 & 5.7 \\
\hline Center mirror & 16.4 & 27.4 & 6.6 & 15.7 \\
\hline Driver-side mirror & 23.2 & 36.2 & 9.5 & 28.4 \\
\hline
\end{tabular}




\section{DISCUSSION}

\section{Comparison of the actual and expected illuminances (Part 1)}

For each of the 22 test vehicles, we calculated the expected illuminances at each of the 12 points. These calculations took into account the actual mounting positions of the two lamps on each individual vehicle, and the corresponding laboratory photometric data for the respective vehicle class in Sivak et al. (1997). The median expected illuminances are shown in Table 7. The median actual illuminances (from Table 5) as percentages of the expected illuminances (from Table 7) are listed in Table 8 . We will return to the patterns in Table 8 after we discuss the effects of dirt, voltage, misaim, and pavement reflectance.

Table 7

Median expected illuminances in lux based on laboratory photometric measurements in Sivak et al. (1997).

\begin{tabular}{|l|c|c|c|c|}
\hline \multirow{2}{*}{\begin{tabular}{c}
\multirow{2}{*}{$\begin{array}{c}\text { Glare } \\
\text { scenario }\end{array}$} \\
\cline { 2 - 5 }
\end{tabular}} & \multicolumn{3}{|c|}{ Clared vehicle type } \\
\cline { 2 - 5 } & $25 \mathrm{~m}$ & $50 \mathrm{~m}$ & $25 \mathrm{~m}$ & $50 \mathrm{~m}$ \\
\hline \hline Oncoming driver & 0.78 & 0.42 & 0.60 & 0.29 \\
\hline Center mirror & 1.54 & 0.93 & 1.05 & 0.47 \\
\hline Driver-side mirror & 4.95 & 3.00 & 2.91 & 1.83 \\
\hline
\end{tabular}

Table 8

The median actual illuminances (from Table 5) as percentages of the median expected illuminances (from Table 7).

\begin{tabular}{|l|c|c|c|c|}
\hline \multirow{2}{*}{\begin{tabular}{c}
\multirow{2}{*}{$\begin{array}{c}\text { Glare } \\
\text { scenario }\end{array}$} \\
\cline { 2 - 5 }
\end{tabular}} & \multicolumn{3}{|c|}{ Car } & \multicolumn{3}{c|}{ Light truck, van, or SUV } \\
\cline { 2 - 5 } & $25 \mathrm{~m}$ & $50 \mathrm{~m}$ & $25 \mathrm{~m}$ & $50 \mathrm{~m}$ \\
\hline \hline Oncoming driver & 160 & 136 & 172 & 162 \\
\hline Center mirror & 166 & 119 & 188 & 174 \\
\hline Driver-side mirror & 68 & 83 & 81 & 87 \\
\hline
\end{tabular}




\section{Effects of dirt}

Dirt deposits on headlamp lenses have two major effects: a reduction in the total amount of emitted light and an increase in scattered light. Sivak, Flannagan, Traube, Kojima, and Aoki (1996) have shown that the relation between "dirty" and "clean" luminous intensities is well described by a linear function $y=a x+b$, where

$y$ is the "dirty" luminous intensity,

$x$ is the "clean" luminous intensity,

$a$, the slope $(<1)$ specific to the dirt accumulation in question, is an estimate of the proportional reduction in luminous intensity throughout the beam pattern caused by both absorption and scattering, and

$b$, the intercept specific to the dirt accumulation in question, is an estimate of the amount of the superimposed luminous intensity caused by scattering.

The net result of these effects is to increase intensities at points in the beam pattern that have relatively low intensity when the lamp is clean, and to decrease intensities at points that have relatively high intensity when the lamp is clean (Sivak, Flannagan, Traube, Kojima, and Aoki, 1996).

Applying those findings to the present data leads to a prediction that the expected glare illuminances (based on measurements with clean headlamps) involving points in the beam pattern that are relatively weak should underestimate the actual illuminances. Conversely, the expected illuminances involving points in the beam pattern that are relatively strong should overestimate the actual illuminances.

To test this prediction, we calculated the luminous intensities that the lamps needed to emit to produce the median actual glare illuminances in Table 5 and the median expected illuminances in Table 7. (These calculations assumed equal contributions from the two lamps.) These two sets of luminous intensities are shown in Table 9. Consistent with the prediction, the expected luminous intensities that were less than 1,200 cd tended to underestimate the actual intensities, while the expected luminous intensities that were more than 1,200 cd tended to overestimate the actual intensities. (There was only one exception to this general pattern.) To describe this relation formally, we regressed the actual intensities on the expected intensities (both from Table 9). The results (see Figure 2) are, again, consistent with the findings of Sivak, Flannagan, Traube, Kojima, and Aoki (1996). Specifically, the relation is very well described by a linear function, with a slope of less than 1 and a positive intercept $(y=0.72 x+314)$. The regression accounted for $94 \%$ of the variance in the actual intensities. 
Table 9

The median actual luminous intensities (first entries) and the median expected luminous intensities (second entries) directed towards the 12 test locations (from each lamp, in candela). (Calculated from the median actual illuminances in Table 5 and the median expected illuminances in Table 7.)

\begin{tabular}{|l|c|c|c|c|}
\hline \multirow{2}{*}{\begin{tabular}{c}
\multirow{2}{*}{$\begin{array}{c}\text { Glare } \\
\text { scenario }\end{array}$} \\
\cline { 2 - 5 }
\end{tabular}} & \multicolumn{3}{|c|}{ Car } & \multicolumn{4}{c|}{ Light truck, van, or SUV } \\
\cline { 2 - 5 } & $25 \mathrm{~m}$ & $50 \mathrm{~m}$ & $25 \mathrm{~m}$ & $50 \mathrm{~m}$ \\
\hline \hline Oncoming driver & $391 / 244$ & $713 / 525$ & $322 / 188$ & $588 / 362$ \\
\hline Center mirror & $800 / 481$ & $1,388 / 1,163$ & $616 / 328$ & $1,025 / 588$ \\
\hline Driver-side mirror & $1,059 / 1,547$ & $3,100 / 3,750$ & $738 / 909$ & $1,988 / 2,288$ \\
\hline
\end{tabular}

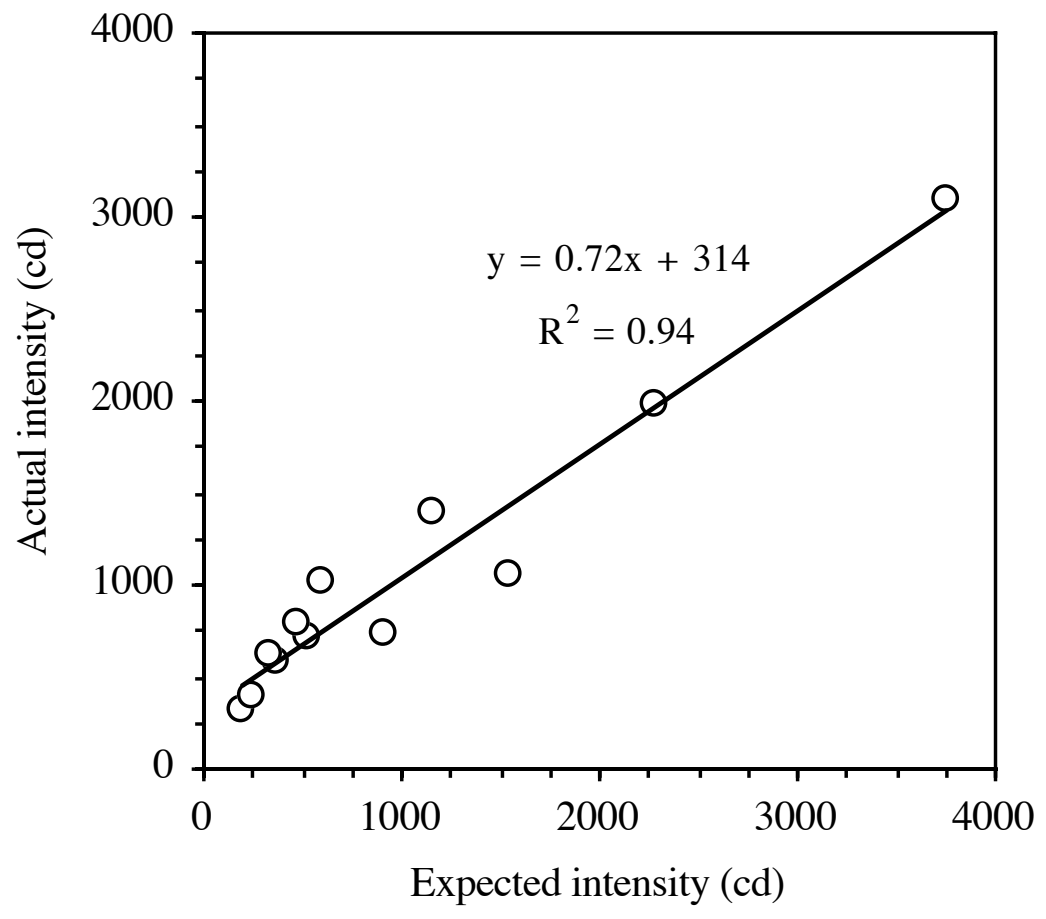

Figure 2. The relationship between the actual and expected luminous intensities based on the laboratory measurements of clean lamps by Sivak et al. (1997). 


\section{Effects of voltage}

The light output of headlamps increases in a predictable way when the applied voltage is increased. For example, an increase from $12.8 \mathrm{~V}$ to $13.5 \mathrm{~V}$ results in an increase in light output of about 20\% (Sivak, Flannagan, Traube, and Miyokawa, 1998). The laboratory photometric measurements by Sivak, Flannagan, Kojima, and Traube (1997) were taken at $12.8 \mathrm{~V}$. However, current vehicles tend to have somewhat higher operating voltages (Sivak, Flannagan, and Miyokawa, 1999b). On the other hand, the present readings were done with engine at idle.

Because voltage has proportionally the same effect throughout the beam pattern (Sivak, Flannagan, Traube, and Miyokawa, 1998), combined effects of voltage and dirt could still be modeled by a linear function, as was the case for the effects of dirt only. However, if the actual voltage was greater than $12.8 \mathrm{~V}$, the slope of the linear function for the combined effects would be greater than the slope for the effects of dirt only. Conversely, if the actual voltage was smaller than $12.8 \mathrm{~V}$, the slope for the combined function would be smaller than the slope for the effects of dirt only.

\section{Effects of misaim}

Lamps misaimed up would produce more light at our test points than expected; conversely, lamps misaimed down would produce less light than expected. However, the data from two recent U.S. surveys indicate that the mean vertical aim of in-use lamps is close to the nominal aim: The mean vertical aim in Olson and Winkler (1985) was about $-0.15^{\circ}$, while in Copenhaver and Jones (1992) it was about $+0.04^{\circ}$. Consequently, the overall effects of misaim on the discrepancy between the median actual and the median expected illuminances is likely to be small.

\section{Effects of pavement reflectance}

The illuminances measured in this study depend not only on direct illumination but also on illumination reflected from the pavement. The light-reflecting properties of pavements are quite complex (e.g., Jackett and Fisher, 1974; Sabey, 1972). Thus, it would be difficult to estimate analytically the differential contribution of the pavementreflected light on the illuminances in the 12 individual test locations. However, it would be rather easy to evaluate empirically in future studies (e.g., by use of appropriate baffles). 


\section{Comparison of the actual and expected illuminances (Part 2)}

Now that we have discussed the likely effects of dirt, voltage, misaim, and pavement reflectance, let us attempt to account for the relationships between the actual and expected illuminances evident in Table 8 . The three main patterns in Table 8 are as follows:

(1) The actual illuminances are always greater than the expected illuminances for oncoming drivers and for preceding drivers via center mirrors, and they are always smaller than the expected illuminances for preceding drivers via driver-side mirrors.

This is consistent with dirt increasing the luminous intensity at the relatively weak points in the beam pattern and decreasing the luminous intensity at the relatively strong points in the beam pattern. (The four expected luminous intensities in the direction of the driver-side mirror are the first, second, third, and fifth highest among the set of the twelve expected intensities in Table 9).

(2) In percentage terms, the disparities between the actual and expected illuminances were always smaller at $50 \mathrm{~m}$ than at $25 \mathrm{~m}$. This was true both for points that were overpredicted (driver-side mirrors) and for points that were underpredicted (oncoming drivers and center mirrors).

The magnitude and direction of prediction errors for the three scenarios are guaranteed to converge eventually with increasing distance simply because the angles corresponding to the three scenarios all converge on one point ( $\mathrm{HV}$, at the headlamp axis) as distance increases. However, this fact alone does not mean that the errors at longer distances must converge on zero, no matter what the direction of error at shorter distances, as they do in this case. Photometric prediction of the HV point could still be either too high or too low. Whether the greater accuracy of predictions at $50 \mathrm{~m}$ in the present case is due simply to the general convergence on $\mathrm{HV}$ - or to more systematic effects of dirt, aim, pavement reflectance or other factors-is difficult to determine without further field measurements. 

greater when the glared vehicle is a light truck, van, or SUV as opposed to a car.

This pattern is consistent with the effect of dirt. Figure 3 presents a schematic representation of how the relationship between actual and expected luminous intensities is affected by dirt. As discussed above, when there is dirt on the face of a lamp this relationship is well described by a linear function with a slope of less than 1 and a positive intercept. It is evident from Figure 3 that the actual luminous intensity as a percentage of the expected luminous intensity increases as the absolute luminous intensity decreases (i.e., as you move from right to left on the horizontal axis in Figure 3). Examining the expected intensities for the two different types of glared vehicles in Table 9, we find that the expected intensities for light trucks, vans, and SUVs are always less than those for cars. (This is the case because the driver eye position and the mirror positions are higher in light trucks, vans, and SUVs than in cars.) Consequently, we would expect that dirt would cause the actual illuminances as percentages of the expected illuminances to be greater for light trucks, vans, and SUVs. This would be true whether the actual values for the two vehicle types were both less than the corresponding expected values (as on the right side of Figure 3) or both greater than the corresponding expected values (as on the left side of Figure 3). Both of these patterns occur in Table 9, and both are potentially explained by the effects of dirt.

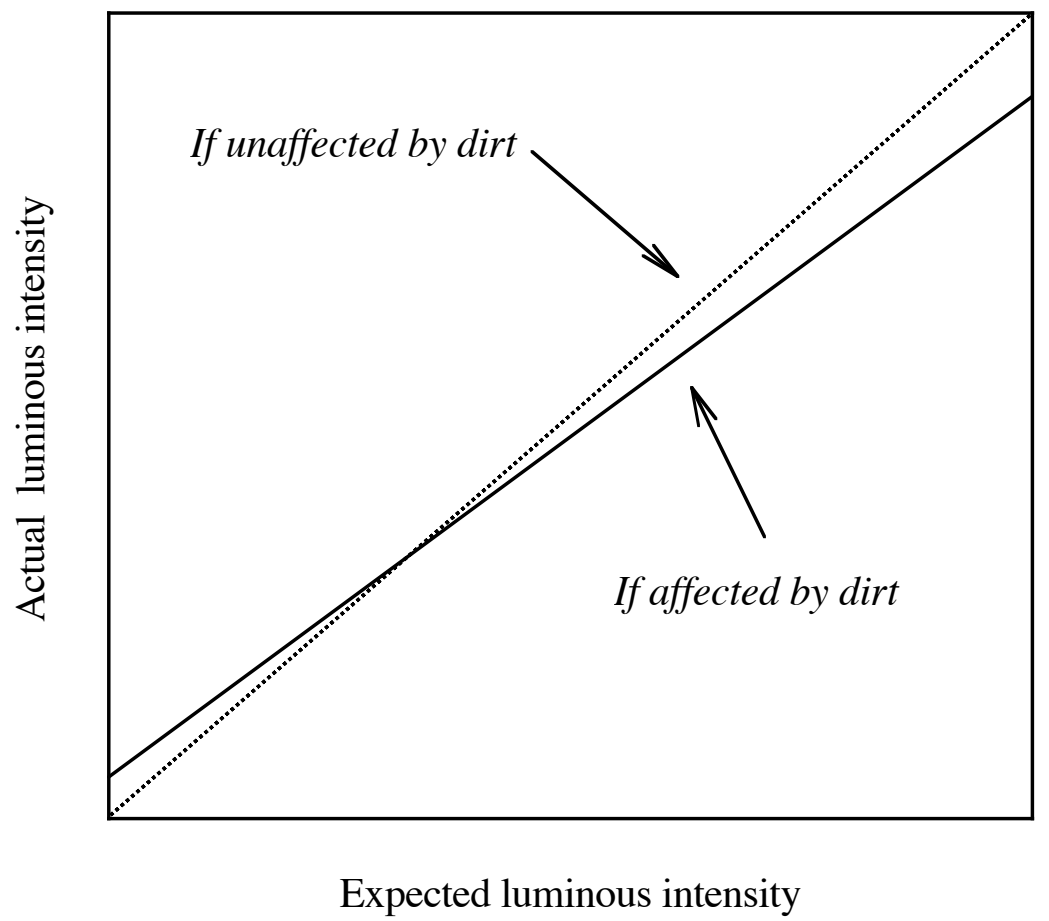

Figure 3. A schematic representation of how the relationship between actual and expected luminous intensities is affected by dirt (after Sivak, Flannagan, Traube, Kojima, and Aoki, 1996). 


\section{Lamp mounting height and glare}

For each vehicle tested, we measured the mounting height of the low-beam headlamps. As expected, in each of the 12 conditions, there was a positive relationship between mounting height and glare illuminance. Table 10 lists the slopes of the best-fitting linear equations. The slopes ranged from +0.01 (an increase of 0.01 lux for each increase of $1 \mathrm{~cm}$ ) to +0.20 (an increase of 0.2 lux for each increase of $1 \mathrm{~cm}$ ). Table 11 shows the percentages of variance in glare illuminance accounted for by mounting height in each of the 12 test conditions. These percentages ranged from negligible $(1 \%)$ to moderate $(59 \%)$.

Table 10

Slopes (in lux per $\mathrm{cm}$ ) of the best-fitting linear relationships between lamp mounting height and glare illuminance.

\begin{tabular}{|c|c|c|c|c|}
\hline \multirow{3}{*}{$\begin{array}{c}\text { Glare } \\
\text { scenario }\end{array}$} & \multicolumn{4}{|c|}{ Glared vehicle } \\
\hline & \multicolumn{2}{|c|}{ Car } & \multicolumn{2}{|c|}{ Light truck, van, or SUV } \\
\hline & $25 \mathrm{~m}$ & $50 \mathrm{~m}$ & $25 \mathrm{~m}$ & $50 \mathrm{~m}$ \\
\hline Oncoming driver & 0.04 & 0.02 & 0.02 & 0.01 \\
\hline Center mirror & 0.20 & 0.11 & 0.06 & 0.06 \\
\hline Driver-side mirror & 0.06 & 0.16 & 0.03 & 0.10 \\
\hline
\end{tabular}

Table 11

Percentage of variance in glare illuminance accounted for by lamp mounting height.

\begin{tabular}{|c|c|c|c|c|}
\hline \multirow{3}{*}{$\begin{array}{c}\text { Glare } \\
\text { scenario }\end{array}$} & \multicolumn{4}{|c|}{ Glared vehicle } \\
\hline & \multicolumn{2}{|c|}{ Car } & \multicolumn{2}{|c|}{ Light truck, van, or SUV } \\
\hline & $25 \mathrm{~m}$ & $50 \mathrm{~m}$ & $25 \mathrm{~m}$ & $50 \mathrm{~m}$ \\
\hline Oncoming driver & 39 & 27 & 24 & 26 \\
\hline Center mirror & 59 & 54 & 34 & 50 \\
\hline Driver-side mirror & 1 & 29 & 3 & 22 \\
\hline
\end{tabular}




\section{SUMMARY}

This study measured direct and rearview-mirror glare illuminances produced by low-beam headlamps in a sample of 22 passenger vehicles. The glare illuminances were measured for 12 common glare situations that were defined by a full factorial combination of three scenarios (oncoming driver, center rearview mirror of a preceding driver, or driver-side mirror of a preceding driver one lane to the right), two longitudinal distances $(25 \mathrm{~m}$ or $50 \mathrm{~m}$ ), and two vertical locations (glared vehicle being either a car or a light truck/van/SUV). The measurements were made outdoors at night on asphalt pavement.

The median illuminances ranged from 0.5 lux for an oncoming driver of a light truck/van/SUV at a distance of $50 \mathrm{~m}$, to 3.4 lux at the driver-side mirror of a preceding car at $25 \mathrm{~m}$ one lane to the right. (These values do not take into account window transmittance or mirror reflectance.) The ratios of the maxima and the minima measured for each of the 12 glare situations were large, ranging from about 5:1 to 36:1.

The median actual illuminances were compared to the median expected illuminances based on a recent, laboratory-measured, representative sample of U.S. low-beam patterns, taking into account the possible effects of dirt, voltage, misaim, and pavement reflectance. This analysis indicates that the actual illuminances could be very well modeled using the laboratory-measured beam patterns and assuming a linear relationship between the light output of clean and dirty headlamps. Additional analyses evaluated the relationships between headlamp mounting height and glare illuminance. 


\section{REFERENCES}

Ammerlaan, H. and Vellekoop, L. (1996). A survey of on-board voltages of present M1 vehicles (Informal Document No. 8, presented at the $37^{\text {th }}$ GRE Session). Geneva: GRE.

Copenhaver, M.M. and Jones, E. (1992). Measurement of headlamp aim and the electrical and photometric performance characteristics of rear lighting systems (Report No. DOT HS 807 930). Washington, D.C.: National Highway Traffic Safety Administration.

Cox, N.T. (1968). The effect of dirt on vehicle headlamp performance (Report LR 240). Crowthorne, England: Road Research Laboratory.

Jackett, M.J. and Fischer, A.J. (1974). The light reflecting properties of asphaltic concrete road surfaces. In, Proceedings of the $7^{\text {th }}$ conference of the Australian Road Research Board (pp. 287-306). Adelaide, Australia: Australian Road Research Board.

Olson, P.L. and Winkler, C.B. (1985). Measurement of crash avoidance characteristics of vehicles in use (Report No. UMTRI-85-20). Ann Arbor: The University of Michigan Transportation Research Institute.

Padmos, P. and Alferdinck, J.W.A.M. (1988). Car headlamps: Influence of dirt, age, and poor aim on glare and illumination intensities. Lighting Research and Technology, 20, 195-198.

Reed, M., Lehto, M.M., and Flannagan, M.J. (2000). Field of view in passenger car mirrors (Report No. UMTRI-2000-23). Ann Arbor: The University of Michigan Transportation Research Institute.

Reed, M.P., Ebert, S.M., and Flannagan, M.J. (2001). Mirror field of view in light trucks, minivans, and sport utility vehicles (Report UMTRI-2001-01). Ann Arbor: The University of Michigan Transportation Research Institute.

Rumar, K. (1974). Dirty headlamps - frequency and visibility effects. Ergonomics, 17, 529-533.

Sabey, B.E. (1972). Road surface reflection characteristics (Report LR 490). Crowthorne, England: Transport and Road Research Laboratory.

Silva, D. (1998). Long-term on-vehicle usage and voltage measurements (Interim Report, presented at the GTB Meeting in South Africa). Dearborn, MI: Ford Motor Co.

Sivak, M., Flannagan, M.J., Budnik, E.A., Flannagan, C.C., and Kojima, S. (1996). The locations of headlamps and driver eye positions in vehicles sold in the U.S. (Technical Report No. UMTRI-96-36). Ann Arbor: The University of Michigan Transportation Research Institute. 
Sivak, M., Flannagan, M.J., Kojima, S., and Traube, E.C. (1997). A market-weighted description of low-beam headlighting patterns in the U.S. (Technical Report No. UMTRI-97-37). Ann Arbor: The University of Michigan Transportation Research Institute.

Sivak, M., Flannagan, M.J., and Miyokawa, T. (1999a). Determining the most effective ways of improving current headlighting. In Proceedings of the Conference on Progress in Automotive Lighting (pp. 723-732). Darmstadt, Germany: Darmstadt University of Technology.

Sivak, M., Flannagan, M.J., and Miyokawa, T. (1999b). Recommended test voltage for worldwide harmonized headlamp photometric specifications (Technical Report No. UMTRI-99-3). Ann Arbor: The University of Michigan Transportation Research Institute.

Sivak, M., Flannagan, M.J., and Schoettle, B. (2000). A market-weighted description of low-beam headlighting patterns in Europe (Technical Report No. UMTRI-200036). Ann Arbor: The University of Michigan Transportation Research Institute.

Sivak, M., Flannagan, M.J., Traube, E.C., Kojima, S., and Aoki, M. (1996). Effects of realistic levels of dirt on light distribution of low-beam headlamps (Technical Report No. UMTRI-96-10). Ann Arbor: The University of Michigan Transportation Research Institute.

Sivak, M., Flannagan, M.J., Traube, E.C., and Miyokawa, T. (1998). Do changes in voltage result in proportional changes throughout headlamp beam pattern? (Technical Report No. UMTRI-98-27). Ann Arbor: The University of Michigan Transportation Research Institute. 